\title{
Country and Industry-Level Performance of NASDAQ-Listed European and Asia Pacific ADRs
}

\author{
Mark Schaub ${ }^{1}$ \\ ${ }^{1}$ Department of Economics and Finance, College of Business, Stephen F. Austin State University, USA \\ Correspondence: Mark Schaub, Department of Economics and Finance, College of Business, Stephen F. Austin \\ State University, USA. E-mail: schaubm@sfasu.edu
}

Received: April 4, 2018

doi:10.5539/ijef.v10n6p122
Accepted: April 20, 2018

Online Published: May 10, 2018

URL: https://doi.org/10.5539/ijef.v10n6p122

\begin{abstract}
This study examines the 3-year performance of NASDAQ-Listed Asia Pacific and European ADRs versus the NASDAQ Index and their respective regional indexes from 1990-2010. Country specific performance results show ADRs from China, Japan and Ireland performed best versus the US and regional benchmarks. Industry-level results show the best industry performers were in the Technology Hardware \& Services industry and in Energy companies.
\end{abstract}

Keywords: American depositary receipts, regional indexes, international diversification, country analysis, industry analysis

\section{Introduction}

Portfolio management theory promotes diversification to reduce risk without hurting portfolio returns. A major vehicle for obtaining international diversification for US investors has been by buying foreign company stocks listed in the US as American Depository Receipts (henceforth ADRs). Some previous studies, for example Jiang (1998), and Schaub (2004), show ADRs provide international diversification benefits to US investors. Other studies, such as Pukthuanthong and Roll (2009) and Christoffersen et al. (2012), show these benefits have declined. A more recent study by Schaub and Brown (2015) finds ADR investing, versus investing in regional indexes, may still provide extra diversification benefits to US investors.

While many of the previously listed studies emphasize investing in large firms listed on the New York Stock Exchange, not as much attention has been paid to smaller firms trading as ADRs on the NASDAQ. Historically, smaller firms experience higher levels of return variation that may cause specific industry-level returns to vary significantly from overall stock index returns. For that reason, this paper examines the returns of NASDAQ-listed firms from Europe and the Asia Pacific region to determine industry-level and country-specific performance deviations from both regional and domestic US indexes.

The remainder of this study is broken down as follows: the next section provides a basic background review of the topic. Following that, the methodology section presents the sample composition and computational methods. The last two sections present excess return results and conclude the study.

\section{Background}

ADRs are created by translating the value of a foreign company's stock into dollars and then packaging shares until the total value in dollars reaches the desired trading value of a typical US stock. A receipt (ADR) sold against the bundled shares then trades in the US markets like domestic equities. Bundling the shares does not remove the foreign exchange risk or country risk of the individual ADR. For this reason, diversifying among ADRs from different countries may reduce these risks.

Liang and Mougoue (1996) suggest a well-diversified portfolio of ADRs can diversify away most of the exchange rate risk. Additionally, Karolyi (1998, 2004) suggests ADR-listing from different countries promote global economic activity and bring stability to emerging markets. While diversifying away the exchange rate risk has dominated ADR research, the question remains about the industry-level risks that ADR investors may have exposure to as well as specific country risk (other than merely forex risk). Some individual countries may also have dominant industries that keep their ADR offerings from being as diverse as other countries. 
This study seeks to address the country-level and industry-level differences of ADR returns by examining the performance of NASDAQ-listed ADR issues from countries in the Asia Pacific and European regions. Results based on country returns versus a US index and regional index, as well as differences in industry ADRs versus the same, may indicate risk and return variances at more of a micro-level.

\section{Data and Methodology}

For comparing ADR performance to domestic and regional indexes, a sample was compiled of all ADRs listed from 1990 through the end of 2009 using the NASDAQ and the BNY Mellon websites. In Table 1 the total sample of 152 NASDAQ-traded ADRs are divided by region and listing dates. Table 1 shows the number of ADRs listed from both regions during the 20-year sample period evened out in the 2000's when more Asia Pacific ADRs were listed.

Table 1. Sample description by region and date

\begin{tabular}{cccc}
\hline \multirow{2}{*}{ Region of Issue } & Number of Observations & \multicolumn{2}{c}{ Date of Issue } \\
\cline { 3 - 4 } & 75 & $\mathbf{1 9 9 0 s}$ & $\mathbf{2 0 0 0 s}$ \\
\hline Asia Pacific & 77 & 20 & 55 \\
Europe & 152 & 54 & 23 \\
\hline Totals & 74 & 78 \\
\hline
\end{tabular}

ADR cumulative and excess returns follow the standard ADR and IPO methodology as seen in Schaub (2003). An excess return means the return of the ADR has been adjusted by subtracting the return of the market index in order to determine how the ADR performed versus the benchmark. The results for this study are based on returns from when the ADR was first listed until the end of the third year of trading in the US. The NASDAQ index represents the respective US index (for comparing NASDAQ-listed ADRs to) and the regional indexes are those provided by Morgan Stanley Capital International available in Morningstar (MSCI Europe Index and MSCI Asia Pacific Index). These indexes were available for the entire sample period (1990 through 2010) and represent easy to obtain investment sets for the typical investor.

Equation 1 computes excess returns for each ADR. The market index return in month $t\left(r_{m t}\right)$ is subtracted from the return of the ADR in month $t\left(r_{i t}\right)$ to obtain the excess return for ADR i during month $t\left(\mathrm{xr}_{\mathrm{it}}\right)$.

$$
x r_{i t}=r_{i t}-r_{m t}
$$

Equation 2 computes the average excess return for the sample of ADRs during month t. The average excess return $\left(\mathrm{XR}_{\mathrm{t}}\right)$ results from dividing the sum of the excess returns by the number $(\mathrm{n})$ of securities in the sample.

$$
X R_{t}=\frac{1}{n} \sum_{i=1}^{n} x r_{i t}
$$

In Equation 3, the cumulative excess returns (CXR) for the three years is the sum of the average excess returns starting at month 1 until month 36 (s ends at 36 for 3 year returns).

$$
C X R_{1, s}=\sum_{t=1}^{s} X R_{t}
$$

$\mathrm{P}$-values for average 3-year cumulative excess returns indicate whether the excess returns are significant using an alpha level of .10 .

\section{Results and Discussion}

In Tables 2 through 4, basic sample return statistics show how the NASDAQ-listed ADRs performed versus the relative benchmarks with an emphasis placed on country of issue and industry. Each table describes the excess performance of the respective ADR sample versus the NASDAQ on the left side of each panel (US index) and the regional index (MSCI for that region) on the right side.

Table 2. Performance statistics by European sample and country

\begin{tabular}{lrllr}
\hline \multicolumn{2}{c}{ Panel A. Performance Statistics of European Sample } & & & \multicolumn{2}{c}{ European ADR Sample Versus EUR MSCI } \\
\hline Highest CXR & $475.0 \%$ & & Highest CXR & $451.2 \%$ \\
Lowest CXR & $-234.9 \%$ & & Lowest CXR & $-218.6 \%$ \\
Mean CXR & $15.9 \%$ & & Mean CXR & $26.8 \%$ \\
Median CXR & $9.6 \%$ & & Median CXR & $-0.1 \%$ \\
Observations $>0$ & 41 & & Observations $>0$ & 38 \\
Observations $<0$ & 36 & & Observations $<0$ & 39 \\
\hline
\end{tabular}




\begin{tabular}{|c|c|c|c|c|c|c|c|}
\hline \multicolumn{8}{|c|}{ Panel B. Average Cumulative Excess Returns by Country } \\
\hline \multicolumn{4}{|c|}{ European ADR Sample Versus NASDAQ } & \multicolumn{4}{|c|}{ European ADR Sample Versus EUR MSCI } \\
\hline Country & Avg. CXR & P-Value & Obs. & Country & Avg. CXR & P-Value & Obs. \\
\hline France & $16.9 \%$ & 0.38 & 10 & France & $32.5 \%$ & 0.27 & 10 \\
\hline Germany & $35.0 \%$ & 0.34 & 7 & Germany & $31.0 \%$ & 0.35 & 7 \\
\hline Ireland & $39.7 \%$ & 0.06 & 8 & Ireland & $62.0 \%$ & 0.02 & 8 \\
\hline Netherlands & $2.6 \%$ & 0.48 & 6 & Netherlands & $18.9 \%$ & 0.35 & 6 \\
\hline Sweden & $-13.6 \%$ & 0.34 & 7 & Sweden & $20.1 \%$ & 0.27 & 7 \\
\hline UK & $11.4 \%$ & 0.34 & 26 & UK & $14.6 \%$ & 0.31 & 26 \\
\hline
\end{tabular}

Note. The European sample contains 77 ADRs listed on the NASDAQ from January 1, 1990 through December 31, 2009. The computation of average excess returns (XR) is described in equation 2 in the text and the computation of cumulative excess returns (CXR) is described in equation 3 in the text. Results are only reported for countries with 5 or more ADRs in the sample.

Table 2 presents basic 3-year cumulative return performance analysis of the European sample of NASDAQ-listed ADRs. Overall, more European ADRs outperformed the NASDAQ than the regional index, however the average excess returns relative to the regional index were higher and show a larger skew (mean versus median). The giant difference between the highest and lowest ADR excess returns shows a huge variance in ADR excess returns. Panel B of Table 2 suggests the NASDAQ-listed ADRs from Ireland, Germany and France were the top performers from the region relative to both indexes. Of special note are the ADRs from Sweden that underperformed the US index but outperformed the regional index. The overall results suggest European NASDAQ-listed ADRs provided consistent outperformance or similar perfomrance relative to the US and European indexes with that one exception.

Table 3. Performance statistics by Asia Pacific sample and country

\begin{tabular}{|c|c|c|c|c|c|c|c|}
\hline \multicolumn{8}{|c|}{ Panel A. Performance Statistics of Asia Pacific Sample } \\
\hline \multicolumn{4}{|c|}{ Asia Pacific ADR Sample Versus NASDAQ } & \multicolumn{4}{|c|}{ Asia Pacific ADR Sample Versus AP MSCI } \\
\hline Highest CXI & & & $516.8 \%$ & Highest CXR & & & $495.3 \%$ \\
\hline Lowest CXR & & & $-213.0 \%$ & Lowest CXR & & & $-240.6 \%$ \\
\hline Mean CXR & & & $10.3 \%$ & Mean CXR & & & $15.3 \%$ \\
\hline Median CXF & & & $3.9 \%$ & Median CXF & & & $8.7 \%$ \\
\hline Observation & & & 38 & Observations & & & 40 \\
\hline Observation & & & 37 & Observations & & & 35 \\
\hline \multicolumn{8}{|c|}{ Panel B. Average Cumulative Excess Returns by Country } \\
\hline \multicolumn{4}{|c|}{ Asia Pacific ADR Sample Versus NASDAQ } & \multicolumn{4}{|c|}{ Asia Pacific ADR Sample Versus AP MSCI } \\
\hline Country & Avg. CXR & P-Value & Obs. & Country & Avg. CXR & P-Value & Obs. \\
\hline Australia & $-54.9 \%$ & 0.08 & 9 & Australia & $-15.2 \%$ & 0.38 & 9 \\
\hline China & $29.6 \%$ & 0.07 & 33 & China & $26.2 \%$ & 0.09 & 33 \\
\hline Hong Kong & $-47.2 \%$ & 0.04 & 12 & Hong Kong & $-34.2 \%$ & 0.09 & 12 \\
\hline Japan & $28.7 \%$ & 0.20 & 7 & Japan & $46.0 \%$ & 0.03 & 7 \\
\hline
\end{tabular}

Note. The Asia Pacific sample contains 75 ADRs listed on the NASDAQ from January 1, 1990 through December 31, 2009. The computation of average excess returns (XR) is described in equation 2 in the text and the computation of cumulative excess returns (CXR) is described in equation 3 in the text. Results are only reported for countries with 5 or more ADRs in the sample.

In Table 3, the 3-year excess return performance of NASDAQ-listed ADRs from the Asia Pacific region versus the US and regional indexes are presented. The sample returns versus both indexes seem nearly normally distributed as the median and mean values are not extremely different. However the country analysis suggests winners and losers based on where the firms were headquartered. Those from Australia and Hong Kong significantly underperformed the US and regional benchmarks, while those ADRs from China and Japan outperformed the benchmarks. The majority of Asia Pacific ADRs listed on the NASDAQ were Chinese firms by a long shot. During the sample period that country also represented the biggest emerging economy of the region. 
Table 4. Average 3-year cumulative excess returns by industry

\begin{tabular}{|c|c|c|c|c|c|}
\hline Industry & $\begin{array}{c}\text { Average CXR } \\
\text { Versus NASDAQ }\end{array}$ & P-Value & $\begin{array}{c}\text { Average CXR } \\
\text { Versus MSCI }\end{array}$ & P-Value & $\begin{array}{c}\text { Number of } \\
\text { Observations }\end{array}$ \\
\hline Diversified Industrial & $-1.60 \%$ & 0.48 & $-10.72 \%$ & 0.38 & 8 \\
\hline Energy & $65.11 \%$ & 0.09 & $92.08 \%$ & 0.06 & 6 \\
\hline Biotech \& Pharmaceutical & $-11.20 \%$ & 0.28 & $-4.66 \%$ & 0.41 & 25 \\
\hline Communications \& Telecom & $27.50 \%$ & 0.26 & $32.13 \%$ & 0.22 & 14 \\
\hline Media \& Broadcasting & $-5.58 \%$ & 0.43 & $11.08 \%$ & 0.38 & 10 \\
\hline Consumer Goods \& Services & $-0.04 \%$ & 0.49 & $3.65 \%$ & 0.45 & 16 \\
\hline Semiconductors & $15.46 \%$ & 0.35 & 15.46 & 0.37 & 10 \\
\hline Software & $22.76 \%$ & 0.20 & $26.72 \%$ & 0.19 & 20 \\
\hline Technology Hardware \& Svcs & $101.36 \%$ & 0.01 & $95.81 \%$ & 0.01 & 15 \\
\hline
\end{tabular}

Note. The total sample contains 152 ADRs from the European and Asia Pacific regions listed on the NASDAQ from January 1,1990 through December 31, 2009. The computation of average excess returns (XR) is described in equation 2 in the text and the computation of cumulative excess returns (CXR) is described in equation 3 in the text. Only those industries with five or more observations are reported.

Table 4 presents 3-year excess return results broken down by the most represented industries in the overall sample of European and Asia Pacific NASDAQ-listed ADRs. Nine different broad industries accounted for 124 of the 152 ADRs. Of the industries, the one with the most ADRs (Biotech \& Pharmaceutical) also had the worst overall excess performance relative to the NASDAQ index. The 15 firms listed from Technology, Hardware, and Services provided superior excess performance relative to both the US and regional benchmarks while the energy firms were the second best performers. The overall sample of ADRs seems well diversified based on the industry representation.

\section{Concluding Comments}

This study presents results that distill the excess returns of ADRs based on countries and industries. Unlike most other ADR performance studies, this one focuses on mostly smaller firm ADRs that list on the NASDAQ. These tend to have more volatile returns than the larger firms that list on the NYSE.

Country-specific results show that, of the ADRs listed from some European countries, only Ireland significantly outperformed both the US and regional index. Some high excess returns did not test statistically significant probably due to the low number of observations or extreme variability in returns. In the Asia Pacific country results, three of the four countries had significant performance or underperformance relative to the market index proxies. Therefore, there are significant differences in country-level performance.

Industry results show Technology Hardware \& Services industry ADRs and Energy company ADRs outperformed the NASDAQ and the respective regional index. The most interesting take away from those results are the variations from industry to industry. Overall, the results of this study suggests that ADRs contain both country and industry risks. Distilling the performance data into these subsets show that ADR portfolios must not only be diverse as to the country of issue but also the industries represented.

\section{References}

Christoffersen, P., Errunza, V., Jacobs, K., \& Langlois, H. (2012). Is the Potential for International Diversification Disappearing? A Dynamic Copula Approach. The Review of Financial Studies, 25(12), 3711-3751. https://doi.org/10.1093/rfs/hhs104

Jiang, C. (1998). Diversification with American Depository Receipts: The Dynamics and the Pricing Factors. Journal of Business, Finance \& Accounting, 25(5-6), 683-699. https://doi.org/10.1111/1468-5957.00207

Karolyi, G. A. (1998). Why Do Companies List Shares Abroad? A Survey of the Evidence and Its Managerial Implications. Financial Markets, Institutions \& Instruments, $\quad 7(1), \quad 1-60$. https://doi.org/10.1111/1468-0416.00018

Karolyi, G. A. (2004). The Role of American Depository Receipts in the Development of Emerging Equity Markets. The Review of Economics and Statistics, 86(3), 670-690. https://doi.org/10.1162/0034653041811699

Liang, Y., \& Mougoue, M. (1996). The Pricing of Foreign Exchange Risk: Evidence from ADRs. International Review of Economics and Finance, (5), 377-385. https://doi.org/10.1016/S1059-0560(96)90024-6

Pukthuanthong, K., \& Roll, R. (2009). Global Market Integration: An Alternative Measure and its Application. 
Journal of Financial Economics, 94(2), 214-232. https://doi.org/10.1016/j.jfineco.2008.12.004

Schaub, M. (2003). Investment Performance of American Depository Receipts Listed on the New York Stock Exchange: Long and Short. Journal of Business and Economic Studies, 9(2), 1-19.

Schaub, M. (2004). Market Timing Wealth Effects of Asia Pacific and European ADRs Traded on the NYSE. Applied Financial Economics, 14(15), 1059-1066. https://doi.org/10.1080/09603100412331297658

Schaub, M., \&Brown, T. (2015). Long Term ADR Performance: How Do Regional Issues Listed on the NYSE Compare to US and Regional Index Returns? International Journal of Business and Finance Research, 9(3), 45-58.

\section{Copyrights}

Copyright for this article is retained by the author(s), with first publication rights granted to the journal.

This is an open-access article distributed under the terms and conditions of the Creative Commons Attribution license (http://creativecommons.org/licenses/by/4.0/). 